ORIGINAL

\title{
Hormonal Regulation of Acetyl-CoA Carboxylase Isoenzyme Gene Transcription
}

\author{
Li Feng ZHAO, Yasumasa IWASAKI, WANG ZHE, Mitsuru NISHIYAMA, TAKAFUMI TAGUCHI, \\ MAKOTO TSUGITA, MACHIKO KAMBAYASHI, KoZO HASHIMOTO AND YoSHIO TERADA \\ Department of Endocrinology, Metabolism, and Nephrology, Kochi Medical School, Kochi University, Nankoku 783-8505, Japan
}

\begin{abstract}
Both glucocorticoid and insulin are known to have an anabolic effect on lipogenesis. Acetyl-CoA, an intermediate product of glycolysis, is supplied for fatty acid synthesis when carbohydrate intake is sufficient. Acetyl-CoA carboxylase (ACC), consisting of two isoenzymes ACC1 and ACC2, mediates the conversion from acetyl-CoA to malonyl-CoA, and thus plays a key role for the regulation of lipogenesis. In this study, we surveyed the effects of glucocorticoid and insulin on the transcriptional activity of the alternative promoters of ACCs (PI-PIII for ACC1, and PI and PII for ACC2) using the HepG2 human hepatocyte cell line in vitro. We also examined the roles of the insulin and/or glucose-regulated transcriptional factor(s) such as SREBP1c, LXR $\alpha / \beta$, and ChREBP on each promoter of the ACC genes. We found that both insulin and glucocorticoid had potent positive effects on all the promoters examined, and additive effects of both hormones were recognized in ACC1 PI and ACC2 PI. Furthermore, a representative insulin-responsive transcription factor SREBP1c showed significant stimulatory effects on all the promoters of ACC genes, among which those on ACC1 PIII and ACC2 PI were most prominent. On the other hand, the effect of LXR $\alpha$ was rather selective; it showed a marked stimulatory effect only on ACC1 PII. LXR $\beta$ and ChREBP had minimal, if any, effects on some of the promoters. Altogether, our data suggest that insulin and glucocorticoid have positive effects on both ACC1 and ACC2 gene transcription. SREBP1c might be a master regulator of the expression of both genes regardless of the promoter utilized, whereas LXR $\alpha$ seems to play a promoter-specific role. Since ACC1 facilitates lipogenesis by stimulating fatty acid synthesis and ACC2 inhibits lipolysis, both insulin and glucocorticoid seem to play an important role in the pathogenesis of obesity and/or hepatic steatosis.
\end{abstract}

Key words: Acetyl-CoA carboxylase, Fatty acid, Glucocorticoid, Insulin, Obesity

GLUCOSE is catalyzed via the glycolytic pathway to pyruvate and then oxidized to generate ATP. However, excess glucose is converted to fatty acid via the lipogenic pathway by a number of enzymes including acetyl-CoA carboxylase (ACC) [1]. Short-term glucose/lipid metabolism is regulated by allosteric changes of the regulatory enzymes, whereas long-term metabolism is mediated by changes in the transcription of each enzyme gene. Indeed, recent in vivo studies show that the amounts of mRNAs for the enzymes change dynamically in response to both fasting and feeding $[2,3]$. Furthermore, insulin and glucocorticoid, the two major hormones harboring a potent an-

Received Oct. 7, 2009; Accepted Jan. 4, 2010 as K09E-298 Released online in J-STAGE as advance publication Feb. 7, 2010

Correspondence to: Yasumasa IWASAKI, M.D., Ph.D., Department of Endocrinology, Metabolism, and Nephrology, Kochi Medical School, Kochi University, Kohasu, Oko-cho, Nankoku 783-8505, Japan. E-mail: iwasaki@kochi-u.ac.jp abolic effect on triglyceride synthesis, are known to play a major role in the nutrient-dependent regulation of genes involved in the lipid metabolism [4].

ACC consists of two isoenzymes, ACC1 and ACC2 [5-7]. Although both enzymes catalyze the conversion from acetyl-CoA to malonyl-CoA, ACC1 is predominantly expressed in lipogenic tissues such as the liver and the adipose tissue, where the enzyme is located in the cytosole of the cells [7]. ACC1 mediates the initial step of the fatty acid synthesis, and liverspecific ACC1 knockout mice show decreased hepatic triglyceride accumulation, suggesting that $\mathrm{ACC} 1$ plays a crucial role in the regulation of lipogenesis [8]. In contrast, ACC2 is expressed in the skeletal and cardiac muscular tissues as well as in the liver, and is located in the outer membrane of the mitochondria $[7,9]$. Malonyl-CoA, generated by ACC2, is shown to inhibit carnitine palmitoyl-CoA transferase I (CPT1), with the resultant inhibition of mitochondrial $\beta$-oxidation of 
fatty acids. ACC2 knockout mice represent enhanced $\beta$-oxidation, and thus this implies that ACC2 is critical for the regulation of lipolysis [10].

Recent molecular genetic analyses have shown that ACC1 gene has 3 alternative promoters (PI, PII, PIII) [11]. The dominant forms of transcripts in the liver are those derived from PI and PII, whereas transcripts from all three promoters are recognized in the heart and skeletal muscle. ACC2 gene is also under the regulation of 3 different promoters (P0, PI, PII), but only PI and PII are functional in vivo, and PII is the primary promoter in the liver [12]. Alternative promoters are in general regulated differentially in a signaling pathway(s)- and/or transcription factor(s)-dependent manner, and it may also be the case with those of ACC1 and ACC2. However, the effects of insulin and glucocorticoid, the two major regulatory factors of lipogenesis, on the promoter-specific transcriptional regulation of $\mathrm{ACC} 1$ and $\mathrm{ACC} 2$ gene are not clarified yet. Furthermore, the roles of representative insulin and/or carbohydrate-related transcription factors, such as sterol response element binding protein $1 \mathrm{c}$ (SREBP1c), liver $X$ receptor $\alpha$ and $\beta(\mathrm{LXR} \alpha / \beta)$, and carbohydrate response element binding protein (ChREBP), in the regulation of each promoter remain to be elucidated [13-16].

Based on this background, in the present study, we surveyed the impact of insulin and glucocorticoid on the transcriptional activity of each promoter of ACC1 and $\mathrm{ACC} 2$ genes using the human hepatocyte-derived cell line HepG2 in vitro. We also comprehensively examined the possible promoter-specific effect(s) of the three transcriptional factors (SREBP1c, LXRs, and ChREBP) on the ACC1/2 gene expression. Our data obtained showed that insulin and glucocorticoid had potent stimulatory effects on the transcriptional activity of all the promoters examined, supporting the concept that both hormones have an anabolic effect on lipogenesis. Furthermore, the role of SREBP1c as a master regulator of both $\mathrm{ACC} 1$ and $\mathrm{ACC} 2$ gene transcription was suggested.

\section{Materials and Methods}

\section{Reagents and plasmids}

Human insulin was provided by Eli Lilly (Indianapolis, IN, USA). Dexamethasone and forskolin were purchased from Sigma (St. Louis, MO, USA).

The 5'-promoter regions of the human ACC1 PI
( $\approx 2 \mathrm{~kb})$, PII $(\approx 2.0 \mathrm{~kb})$, PIII $(\approx 2.2 \mathrm{~kb})$, ACC2 PI $(\approx 1.3$ $\mathrm{kb})$, and PII $(\approx 1.3 \mathrm{~kb})$ were cloned by PCR $[11,12]$ and incorporated into the pA3Luc luciferase reporter plasmid using standard molecular biology techniques. Expression vectors for human SREBP $1 \mathrm{c}, \mathrm{LXR} \alpha / \beta$, RXR $\alpha$, ChREBP, and Mlx were made by cloning of the cDNAs with RT-PCR technique using total RNAs derived from human cell lines (HepG2, HuH7, and HeLa). Each PCR product was confirmed by sequencing, and then incorporated into the pRC/RSV expression plasmid (Clontech, Mountain View, CA).

\section{Cell culture and experiments}

The human hepatocyte-derived HepG2 cells were maintained in high glucose DMEM (Sigma) supplemented with $10 \%$ fetal bovine serum (FBS) and penicillin/streptomycin under a $5 \% \mathrm{CO}_{2} / 95 \%$ air atmosphere at $37^{\circ} \mathrm{C}$. In each experiment, cells were plated and cultured in 24 -well plates to $50 \%$ confluency. On the next day, the cells were transfected simultaneously with each of the promoter-luciferase plasmids with both human insulin receptor (IR) and glucocorticoid receptor (GR) expression vectors [luciferase plasmid:GR:IR $=4: 1: 1(\mu \mathrm{g})]$ using FuGene 6 transfection reagent (Roche, Indianapolis, IN, USA), and $24 \mathrm{~h}$ later the medium was changed to serum-free medium. This culture condition showed minimal deleterious effect on cell viability up to $72 \mathrm{~h}$ evaluated by CytoTox 96 cytotoxicity assay kit (Promega, Madison, MO) (data not shown). In each experiment, test reagents, in $1000 x$ concentration, were then added directly into the culture medium, and the cells were incubated for the defined time interval. At the end of incubation, the culture medium was removed, and the cells were harvested for the determination of luciferase activity. Ready-to-Glow-secreted luciferase system (Clontech, Takara, Japan) was used as an internal control when a different combination of plasmids was used in an experiment.

\section{Luciferase assay}

Luciferase assay was performed as previously described [17], and light output was measured for $20 \mathrm{sec}$ at room temperature using a luminometer (Berthold Lumat LB9507, Bad Wildbad, Germany).

\section{RT-PCR}

Endogenous expression of each promoter-specific transcript (ACC1 PI-III, ACC2 PI, PII) in HepG2 
A

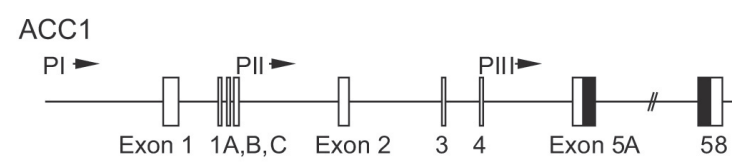

ACC2

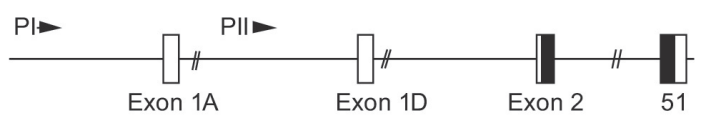

B

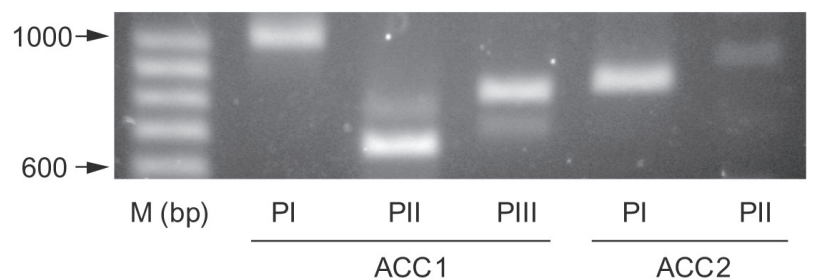

Fig. 1. A. Genomic structure of the 5'-promoter region of human ACC1 and ACC2 genes [11, 12]. B. RT-PCR analysis of the intrinsic expression of 5 different ACC transcripts in HepG2 cells. The photograph shows cDNAs amplified by PCR with pairs of oligonucleotide primers specific for each mRNA. M: molecular size marker (100 bp ladder).

cells was examined by RT-PCR. The cells were plated in 3.5-cm-diameter dishes, and total RNA was extracted using RNeasy RNA extraction kit (Qiagen, Hilden, Germany). One $\mu$ g each was then applied for reverse transcription reaction using Superscript III reverse transcriptase (Invitrogen), followed by PCR reaction $\left(25-30\right.$ cycles, $94^{\circ} \mathrm{C} 30 \mathrm{sec}, 60^{\circ} \mathrm{C} 30 \mathrm{sec}, 72^{\circ} \mathrm{C}$ $2 \mathrm{~min}$ ) using Blend Taq DNA polymerase (Toyobo, Tokyo, Japan). The primer sets used were: for ACC1 sense PI 5'-CGACCAGTAATCACTTTGCCC-3', PII sense 5'-CAGCAGTTCCTCCACGCAGG-3', PIII sense 5'-CTGCAACTAAAGGAGAGCTGC-3', and for common ACC1 antisense 5'-CACTGGCACATAGTGATCTGC-3'; for ACC2 sense PI 5'-CAGAGTAAGCAGCTAGCAGGC-3', PII sense 5'-CCTCACTCAAGAATGGAGCTG-3', and for common ACC2 antisense 5'-GAGAAGCCACGGTAAAGTCTC-3'. The sequences for both sense and antisense primers in each mRNA were obtained from a different exon, to distinguish the mRNA-derived PCR product from the genomic DNA-derived one.

\section{Statistical analysis}

Samples in each group of the experiments were in triplicate or quadruplicate. All data were expressed as a mean \pm SEM. When the statistical analyses were performed, data were compared by one-way analysis

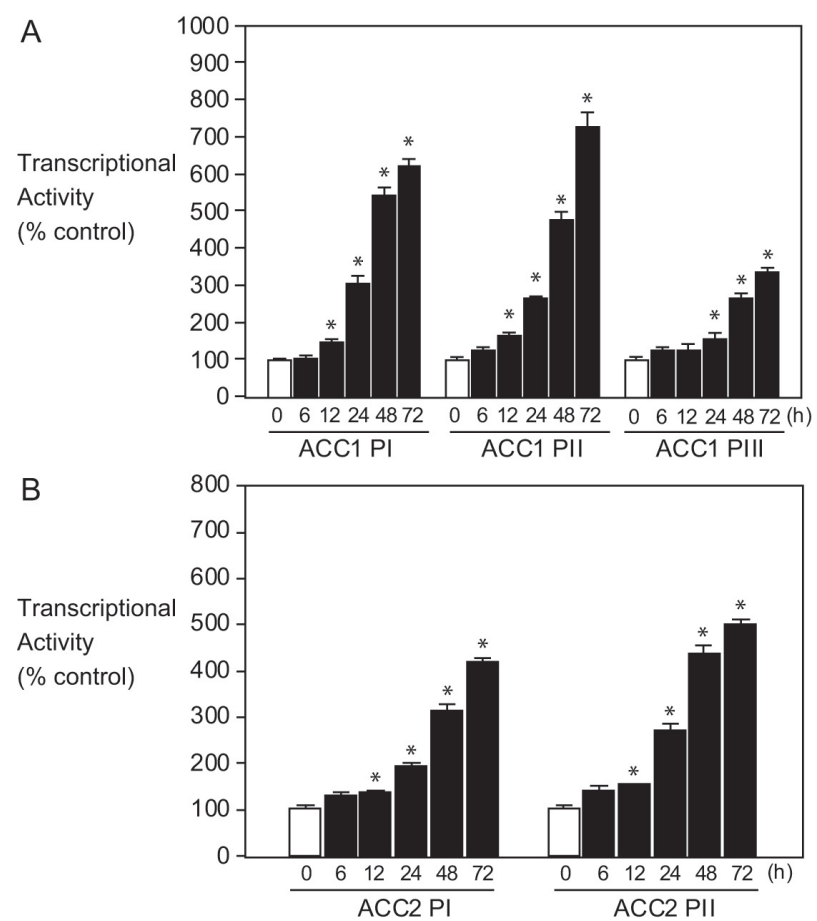

Fig. 2. Time-course effects of insulin on the transcriptional activity of each ACC1 (A) and ACC2 (B) gene promoter. HepG2 cells were transfected transiently with each test plasmid and treated with insulin $(10 \mathrm{nM})$ for up to $72 \mathrm{~h}$. Each value is shown as a percentage of the value at time zero (0). $* P<0.05 v s$. value at time zero.

of variance with Fisher's PLSD test, and $P$ values below 0.05 were considered significant.

\section{Results}

\section{Endogenous expression of each ACC transcript in HepG2 cells}

Human ACC1 and ACC2 mRNAs are regulated by 3 (PI-III) and 2 (PI, PII) promoters, respectively (Fig. 1A) $[11,12]$. We examined the intrinsic expression of transcripts driven by each promoter by RT-PCR. We found that all the transcripts derived from each promoter were amplified (Fig. 1B), indicating that this cell line is appropriate for the transcriptional regulation of all the promoters in vitro.

\section{Time-course effects of insulin on the transcriptional activity of each ACC1/2 gene promoter}

We first examined the effect of insulin on the transcriptional activity of ACC1 PI-III and ACC2 PI, PII promoters. As shown in Fig. 2, insulin significantly enhanced the transcriptional activities of all the pro- 

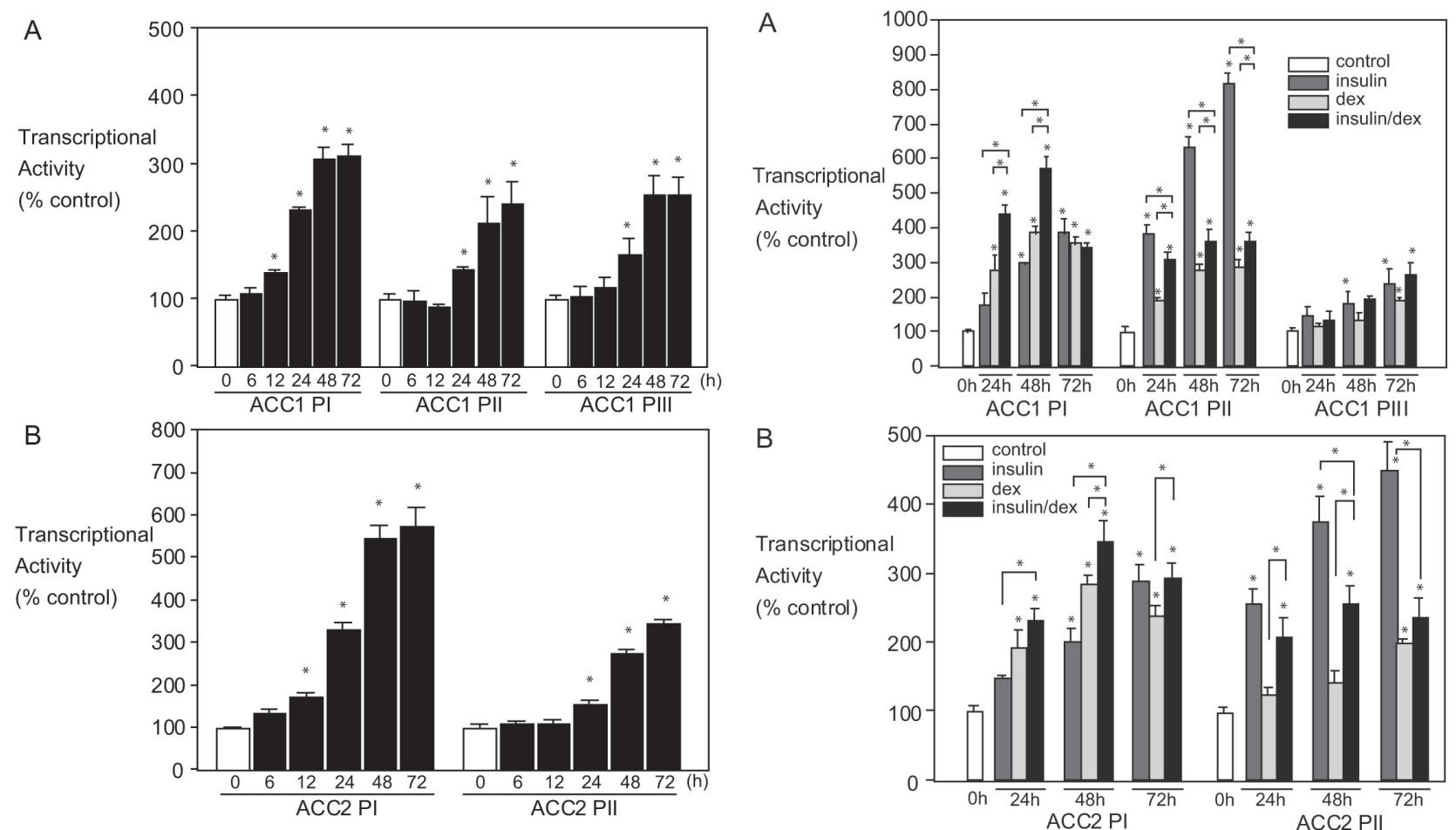

Fig. 3. Time-course effects of glucocorticoid on the transcriptional activity of each ACC1 (A) and ACC2 (B) gene promoter. HepG2 cells were transfected transiently with each test plasmid and treated with dexamethasone $(100 \mathrm{nM})$ for up to $72 \mathrm{~h}$. Each value is shown as a percentage of the value at time zero (0). ${ }^{*} P<0.05 v s$. value at time zero.

moters. Among them, that of ACC1 PII was most prominent ( $>7$-fold increase). Since ACC1 promotes lipogenesis and ACC2 inhibits lipolysis, our data support the concept that insulin is an anabolic hormone for lipid synthesis and storage.

\section{Time-course effects of glucocorticoid on the} transcriptional activity of each $A C C 1 / 2$ gene promoter

We then examined the effect of dexamethasone, a potent synthetic glucocorticoid, on the transcriptional activity of ACC1 PI-III and ACC2 PI, PII promoters. As shown in Fig. 3, dexamethasone significantly stimulated the transcriptional activity of all the promoters, among which that of ACC2 PI was most remarkable ( $\approx 6$-fold increase). These data suggest that glucocorticoid is also an anabolic hormone in terms of fatty acid metabolism.

Combined effects of insulin and glucocorticoid on the transcriptional activity of each ACC1/2 gene promoter

Since insulin and glucocorticoid have anabolic ef-

Fig. 4. Combined effects of glucocorticoid and insulin on the transcriptional activity of $\mathrm{ACC} 1 / 2$ promoter. $\mathrm{HepG} 2$ cells were transfected transiently with each test plasmid and treated with dexamethasone $(100 \mathrm{nM})$ and/or insulin $(10 \mathrm{nM})$ for $24 \mathrm{~h}, 48 \mathrm{~h}$ and $72 \mathrm{~h}$. Each value is shown as a percentage of the value at time zero. ${ }^{*} P<0.05 v s$. value at time zero.

fects on lipogenesis, we then examined the combined effects of both hormones on the transcriptional activity of ACC1 PI-III and ACC2 PI, PII. As shown in Fig. 4, when insulin and dexamethasone were used simultaneously, at 24 and $48 \mathrm{~h}$, the two hormones showed additive effects on ACC1 PI and ACC2 PI promoters. Interestingly, however, dexamethasone showed inhibitory effects on insulin-induced ACC1 PII and ACC2 PII promoter activities. No combined effect was observed in ACC1 PIII promoter.

\section{The effects of SREBP1c and ChREBP co-expression on} the transcriptional activity of each $A C C 1 / 2$ gene promoter

We then examined the effects of the co-expression of lipogenesis-related transcriptional factors, such as SREBP1c and ChREBP, on the transcriptional activity of ACC1 PI-III and ACC2 PI, PII promoters. As shown in Fig. 5A, when SREBP1c expression vector was co-transfected with each ACC promoter, SREBP1c significantly enhanced the transcriptional activity of all the 5 promoters of ACC genes, among 

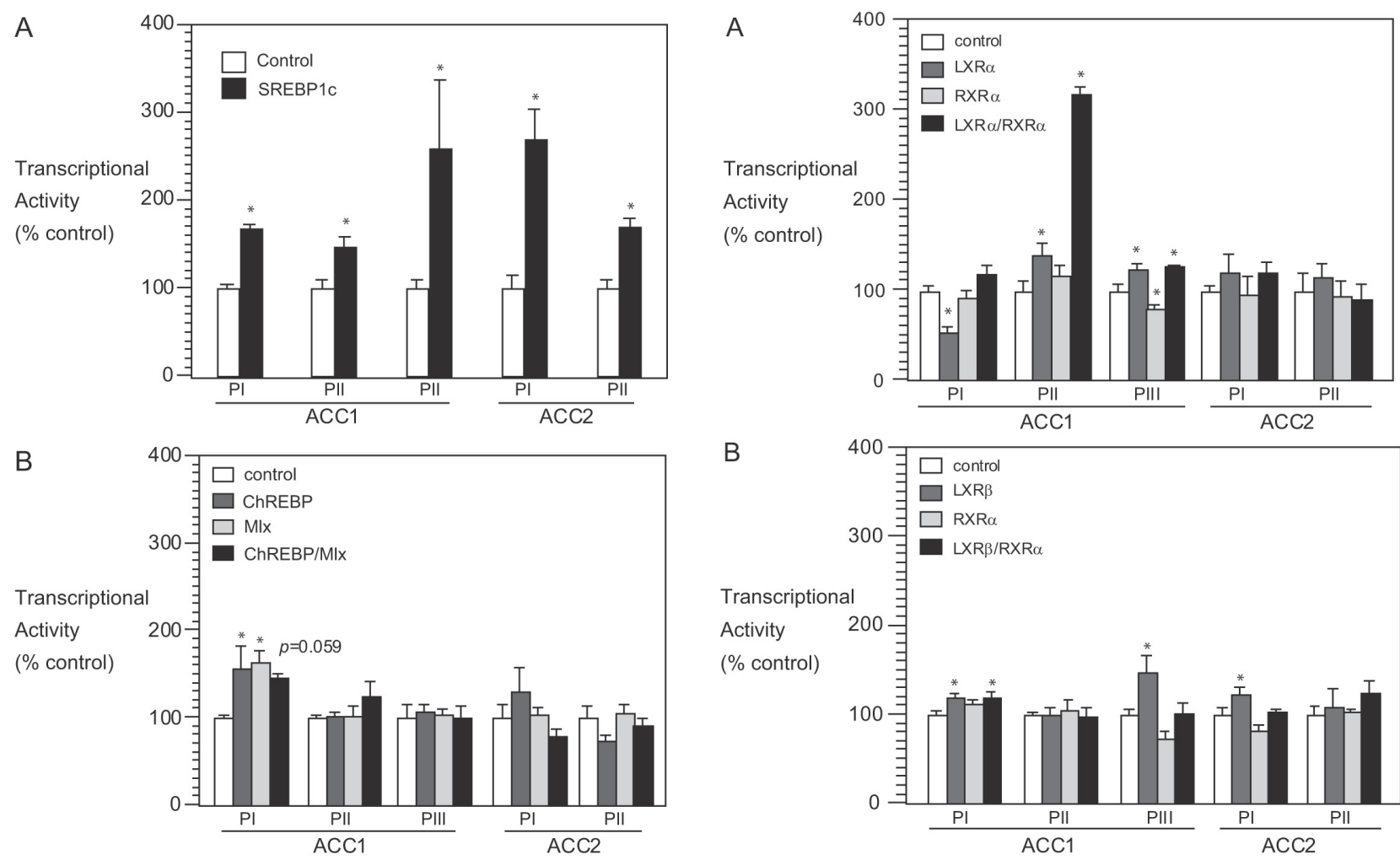

Fig. 5. The effects of SREBP1c and ChREBP on the transcriptional activity of each ACC1/2 gene promoter. A. HepG2 cells were co-transfected with each test plasmid with or without SREBP1c expression vector. B. HepG2 cells were cotransfected with each test plasmid with ChREBP and/or Mlx expression vectors. Each value is shown as a percentage of the corresponding control. ${ }^{*} P<0.05 v s$. control.

which the effects on ACC1 PIII ( $\approx 2.6$-fold increase) and ACC2 PI ( $\approx 2.7$-fold increase) were most remarkable. On the other hand, as shown in Fig. 5B, co-expression of ChREBP/Mlx showed a positive effect only on ACC1 PI. Thus, our data suggest that SREBP1c is the major transcription factor responsible for the expression of $\mathrm{ACC} 1 / 2$ genes, regardless of the promoters used. On the other hand, ChREBP/Mlx seems to play a minimal, if any, role in ACC gene regulation.

\section{The effects of $L X R \alpha / \beta$ co-expression on the}

transcriptional activity of each $A C C 1 / 2$ gene promoter

We finally examined the effects of the co-expression of $L X R \alpha / \beta$ on the transcriptional activity of ACC1 PI-III and ACC2 PI, PII promoters. As shown in Fig. 6A, when $\mathrm{LXR} \alpha / \mathrm{RXR} \alpha$ expression vectors were co-transfected with each ACC promoter, the heterodimer showed a potent stimulatory effect on ACC1

Fig. 6 The effects of $L X R \alpha / \beta$ on the transcriptional activity of each $\mathrm{ACC} 1 / 2$ gene promoter. A. HepG2 cells were cotransfected with each test plasmid with LXR $\alpha$ and/or RXR $\alpha$ expression vectors. B. HepG2 cells were co-transfected with each test plasmid with LXR $\beta$ and/or RXR $\alpha$ expression vectors. Each value is shown as a percentage of the corresponding control. $* P<0.05 v s$. control.

PII ( $\approx 3.2$-fold increase), but had only minimal effects on ACC1 PIII, and did not have any influence on other promoters. In contrast, as shown in Fig. 6B, co-expression of the LXR $\beta / \mathrm{RXR} \alpha$ heterodimer had a minimal or no stimulatory effect on all the promoters examined. These data suggest that $\mathrm{LXR} \alpha / \mathrm{RXR} \alpha$ is involved in the expression of ACC gene via the regulation of specific promoter (ACC1 PII), and that $\mathrm{LXR} \beta / \mathrm{RXR} \alpha$ may not play a major role in $\mathrm{ACC}$ gene expression.

\section{Discussion}

ACCs play important roles in the regulation of triglyceride metabolism in the liver. In this study, we comprehensively surveyed the transcriptional regulation of ACC genes, i.e., multiple promoters of multiple genes, using human hepatocyte-derived HepG2 cells 
in vitro. We found that all the promoters (ACC1 PI-III and ACC2 PI, PII) were positively regulated by both insulin and glucocorticoid, supporting the concept that both hormones are anabolic in nature in terms of lipid metabolism. However, the mode of interaction of the two hormones seems not to be similar among the promoters examined. Furthermore, a different transcription factor(s) is involved in the regulation of each promoter in a distinct manner.

ACC1 is located in the cytoplasm, where it mediates the first step of the fatty acid synthesis by converting acetyl-CoA to malonyl-CoA [7]. On the other hand, ACC2 is shown to exist in the outer membrane of the mitochondria, where the generated malonylCoA inhibits CPT1 and subsequent $\beta$-oxidation of fatty acids [7]. Both isoenzymes are found to be expressed in the liver, and previous studies showed that insulin facilitates ACC gene transcription in hepatocytes both in vitro and in vivo [18-20]. In this paper, we clearly demonstrated that insulin stimulated the transcriptional activities of both ACC1 (PI-PIII) and ACC2 (PI, PII). Since ACC1 promotes lipogenesis and ACC2 inhibits lipolysis, it is reasonable that insulin stimulates all the promoter activities of both ACC1 and ACC2. Our data are also in accordance with the well-accepted concept that insulin is a representative anabolic hormone, and plays an indispensable role in lipid synthesis and storage.

In contrast to insulin, glucocorticoid is involved in the nutritional regulation in a somewhat complicated manner. The hormone has a catabolic effect on protein metabolism, and antagonizes with insulin by enhancing gluconeogenesis and eliciting insulin resistance. In terms of triglyceride metabolism, however, glucocorticoid is known to have an anabolic effect on fatty acid synthesis [21], and chronic excess of the hormone is known to cause steatohepatitis and/or central obesity in Cushing syndrome $[22,23]$. Therefore, it is acceptable that all the promoters of ACC genes are also positively regulated by glucocorticoid, as shown in the current study. Furthermore, our data revealed that glucocorticoid and insulin had additive effects on some of the promoters at the transcriptional level examined, in accordance with a previous study showing the similar cooperative effects at the mRNA level [4]. The reason why glucocorticoid had inhibitory effects on insulininduced promoter activities (ACC1 PII, ACC2 PII) has not been made clear in this study, but it is possible that a competition between GR and insulin-stimulated tran- scription factor(s) might have occurred on the promoter.

Although insulin consistently stimulated the transcriptional activities of $\mathrm{ACC} 1 / 2$, our data strongly suggest that the molecular mechanism may be different among the promoters examined. At least 3 groups of transcriptional factors, SREBP $1 \mathrm{c}, \mathrm{LXR} \alpha / \beta$, and ChREBP/Mlx, are supposed to be involved in the insulin (and glucose)-induced lipogenesis, but the extent to which each factor contributes to the transcription of each promoter has remained to be determined. SREBP1c, one of the basic helix-loop-helix/leucine zipper (bHLH/LZ) transcription factors, is known to be the "master" regulator of lipogenesis, and insulin augments its activity and increases mRNA level as well [13]. In the current study, we found that expression of SREBP1c significantly stimulated all the promoter activities of $A C C 1 / 2$, suggesting strongly that the transcription factors are at least partly mediating the effect of insulin. Interestingly, Mao et al. recently showed that SREBP1a enhanced the PII, but not PI and PIII, activity in HepG2 cells [11], and the mechanism explaining the differential roles of SREBP1 family protein are not clear. However, because SREBP1c rather than SREBP1a is more profoundly involved in the transcriptional regulation of genes related to triglyceride metabolism, and insulin is known to activate SREBP1c [24], we assume that the transcription factor is involved in the insulin effect regardless of the promoters utilized. SREBP1c binds to several types of sterol-response element (SRE) including E-box (CANNTG) [25, 26], which is found to be located in all the promoters examined.

In contrast, $\mathrm{LXR} \alpha$ showed a potent and selective effect on ACC1 PII, and had only minimal or no effect on the other promoters. LXR $\alpha$ is expressed in the liver, and plays an important role in the regulation of lipogenic genes [27]. Although oxysterol was originally thought to be an endogenous ligand, recent studies show that the receptor is activated by glucose as well [28]. Since ACC1 PII promoter contains several putative LXREs (-120/-105 and $-43 /-28 \mathrm{bp}$ ), and the PII promoter is shown to be highly active in hepatocytes [8], we assume that this promoter plays a crucial role in the regulation of insulin/glucose via LXR $\alpha$. Our data also show that LXR $\beta$ has a much smaller, if any, effect on all the ACC promoters examined.

ChREBP, a newly recognized transcription factor, is also shown to be involved in the insulin/glucose-mediated regulation of lipogenic genes [29, 30]. 
ChREBP is, like SREBP1c, a bHLH/LZ transcription factor of the Mondo family, and acts by forming a heterodimer with Max-like protein X (Mlx). The factor is found to regulate the transcription of L-type pyruvate kinase and fatty acid synthase [31] and ACC [32] genes. Unexpectedly, however, our data in this study failed to show a significant stimulatory effect of the transcription factor on all the ACC gene promoters, except that the ChREBP/Mlx heterodimer tended to enhance ACC1 PI. One possibility is that ChREBP/ Mlx alone is not sufficient, and that the co-existence of other factors such as SREBP1c and LXR is needed to cause a significant effect. Alternatively, endogenous ChREBP/Mlx is already stimulated maximally by high glucose medium, and thus additional expression did not cause any further effect, because glucose or its metabolites directly stimulates ChREBP regardless of the presence of insulin. In any event, additional studies are needed to clarify the role of ChREBP in ACC gene regulation.

The liver plays a pivotal role in glucose and lipid metabolism. Insulin is known to activate SREBP1c and/or LXR $\alpha$ in the liver [13, 33], and hyperinsulinemia is one of the causative factors of obesity. In addition, recent basic and clinical studies suggest the role of elevated intracellular and/or extracellular glucocorticoid levels in the metabolic syndrome [34, 35], and our data indeed suggest that glucocorticoid may increase fatty acid storage by promoting $\mathrm{ACC} 1 / 2$ gene transcription. Thus, hyperinsulinemia and/or glucocorticoid excess might cause accumulation of triglyceride partly via the effects of the two hormones on $\mathrm{ACC} 1 / 2$ expression. In this context, pharmacological inhibition of ACC might be a promising therapeutic tool for the prevention of abdominal obesity frequently observed in the metabolic syndrome [36, 37].

\section{Acknowledgement}

This work was supported in part by the Kochi University President's Discretionary Grant.

\section{References}

1. Wakil SJ, Abu-Elheiga LA (2009) Fatty acid metabolism: target for metabolic syndrome. J Lipid Res 50 (Suppl): S138-S143.

2. López-Casillas F, Ponce-Castañeda MV, Kim KH.Mao J, DeMayo FJ (1992) Acetyl-coenzyme A carboxylase mRNA metabolism in the rat liver. Metabolism 41: 201-207.

3. Katsurada A, Iritani N, Fukuda H, Matsumura Y, Nishimoto N, Noguchi T, Tanaka T (1990) Effects of nutrients and hormones on transcriptional and posttranscriptional regulation of acetyl-CoA carboxylase in rat liver. Eur J Biochem 190: 435-441.

4. Salati LM, Clarke SD (1986) Fatty acid inhibition of hormonal induction of acetyl-coenzyme A carboxylase in hepatocyte monolayers. Arch Biochem Biophys 246: 82-89.

5. Abu-Elheiga L, Jayakumar A, Baldini A, Chirala SS, Wakil SJ (1995) Human acetyl-CoA carboxylase: characterization, molecular cloning, and evidence for two isoforms. Proc Natl Acad Sci USA 92: 4011-4015.

6. Abu-Elheiga L, Almarza-Ortega DB, Baldini A, Wakil SJ (1997) Human acetyl-CoA carboxylase 2. Molecular cloning, characterization, chromosomal mapping, and evidence for two isoforms. J Biol Chem 272: 1066910677.

7. Abu-Elheiga L, Brinkley WR, Zhong L, Chirala SS, Woldegiorgis G, Wakil SJ (2000) The subcellular lo- calization of acetyl-CoA carboxylase 2. Proc Natl Acad Sci USA 97: 1444-1449.

8. Mao J, DeMayo FJ, Li H, Abu-Elheiga L, Gu Z, Shaikenov TE, Kordari P, Chirala SS, Heird WC, Wakil SJ (2006) Liver-specific deletion of acetyl-CoA carboxylase 1 reduces hepatic triglyceride accumulation without affecting glucose homeostasis. Proc Natl Acad Sci USA 103: 8552-8557.

9. Kim KW, Yamane H (2006) Expression, purification, and characterization of human acetyl-CoA carboxylase 2. Protein Expr Purif 53: 16-23.

10. Choi CS, Savage DB, Abu-Elheiga L, Liu ZX, Kim S, Kulkarni A, Distefano A, Hwang YJ, Reznick RM, Codella R, Zhang D, Cline GW, Wakil SJ, Shulman GI (2007) Continuous fat oxidation in acetyl-CoA carboxylase 2 knockout mice increases total energy expenditure, reduces fat mass, and improves insulin sensitivity. Proc Natl Acad Sci USA 104: 16480-16485.

11. Mao J, Chirala SS, Wakil SJ (2003) Human acetylCoA carboxylase 1 gene: presence of three promoters and heterogeneity at the 5'-untranslated mRNA region. Proc Natl Acad Sci USA 100: 7515-7520.

12. Oh SY, Lee MY, Kim JM, Yoon S, Shin S, Park YN, Ahn YH, Kim KS (2005) Alternative usages of multiple promoters of the acetyl-CoA carboxylase beta gene are related to differential transcriptional regulation in human and rodent tissues. J Biol Chem 280: 5909-5916. 
13. Shimano H (2001) Sterol regulatory element-binding proteins (SREBPs): transcriptional regulators of lipid synthetic genes. Prog Lipid Res 40: 439-452.

14. Grefhorst A, Elzinga BM, Voshol PJ, Plösch T, Kok T, Bloks VW, van der Sluijs FH, Havekes LM, Romijn JA, Verkade HJ, Kuipers F (2002) Stimulation of lipogenesis by pharmacological activation of the liver $\mathrm{X}$ receptor leads to production of large, triglyceriderich very low density lipoprotein particles. $J$ Biol Chem 277: 34182-34190.

15. Oh SY, Park SK (2003) Acetyl-CoA carboxylase beta gene is regulated by sterol regulatory element-binding protein-1 in liver. J Biol Chem 278: 28410-28407.

16. Denechaud PD, Bossard P, Lobaccaro JM, Millatt L, Staels B, Girard J, Postic C (2008) ChREBP, but not LXRs, is required for the induction of glucose-regulated genes in mouse liver. J Clin Invest 118: 956-964.

17. Aoki Y, Iwasaki Y, Katahira M, Oiso Y, Saito H (1997) Regulation of the rat proopiomelanocortin gene expression in AtT-20 cells. I: Effects of the common secretagogues. Endocrinology 138: 1923-1929.

18. Katz NR, Ick M (1981) Induction of acetyl-CoA carboxylase in primary rat hepatocyte cultures by glucose and insulin. Biochem Biophys Res Commun 100: 703709.

19. Choi DH, Choi JH, Whang SK, Kim YS (1989) Regulation of acetyl CoA carboxylase mRNA in rat liver by high carbohydrate diet and insulin. Yonsei Med J 30: 235-245.

20. Fukuda H, Katsurada A, Iritani N (1992) Nutritional and hormonal regulation of mRNA levels of lipogenic enzymes in primary cultures of rat hepatocytes. $J$ Biochem 111: 25-30.

21. Diamant S, Shafrir E (1975) Modulation of the activity of insulin-dependent enzymes of lipogenesis by glucocorticoids. Eur J Biochem 53: 541-546.

22. Yanovski JA, Cutler GB Jr (1994) Glucocorticoid action and the clinical features of Cushing's syndrome. Endocrinol Metab Clin North Am 23: 487-509.

23. Rockall AG, Sohaib SA, Evans D, Kaltsas G, Isidori AM, Monson JP, Besser GM, Grossman AB, Reznek RH (2003) Hepatic steatosis in Cushing's syndrome: a radiological assessment using computed tomography. Eur J Endocrinol 149: 543-548.

24. Mounier C, Posner BI (2006) Transcriptional regulation by insulin: from the receptor to the gene. Can $J$ Physiol Pharmacol 84: 713-724.

25. Yokoyama C, Wang X, Briggs MR, Admon A, Wu J, Hua X, Goldstein JL, Brown MS (1993) SREBP-1, a basic-helix-loop-helix-leucine zipper protein that controls transcription of the low density lipoprotein recep- tor gene. Cell 75: 187-197.

26. Kim JB, Spotts GD, Halvorsen YD, Shih HM, Ellenberger T, Towle HC, Spiegelman BM (1995) Dual DNA binding specificity of ADD1/SREBP1 controlled by a single amino acid in the basic helix-loop-helix domain. Mol Cell Biol 15: 2582-2588.

27. Wójcicka G, Jamroz-Wiśniewska A, Horoszewicz K, Bełtowski J (2007) Liver X receptors (LXRs). Part I: structure, function, regulation of activity, and role in lipid metabolism. Postepy Hig Med Dosw 61: 736-759.

28. Mitro N, Mak PA, Vargas L, Godio C, Hampton E, Molteni V, Kreusch A, Saez E (2007) The nuclear receptor LXR is a glucose sensor. Nature 445: 219-223.

29. Ishii S, Iizuka, Miller BC, Uyeda K (2004) Carbohydrate response element binding protein directly promotes lipogenic enzyme gene transcription. Proc Natl Acad Sci USA 101: 15597-15602.

30. Postic C, Dentin R (2007) ChREBP, a transcriptional regulator of glucose and lipid metabolism. Annu Rev Nutr 27: 179-192.

31. Da Silva Xavier G, Rutter GA, Diraison F, Andreolas C, Leclerc I (2006) ChREBP binding to fatty acid synthase and L-type pyruvate kinase genes is stimulated by glucose in pancreatic beta-cells. J Lipid Res 47: 2482-1491.

32. Tsatsos NG, Towle HC (2006) Glucose activation of ChREBP in hepatocytes occurs via a two-step mechanism. Biochem Biophys Res Commun 340: 449-456.

33. Tobin KA, Ulven SM, Schuster GU, Steineger HH, Andresen SM, Gustafsson JA, Nebb HI (2002) Liver $\mathrm{X}$ receptors as insulin-mediating factors in fatty acid and cholesterol biosynthesis. J Biol Chem 277: 1069110697.

34. Iwasaki Y, Takayasu S, Nishiyama M, Tsugita M, Taguchi T, Asai M, Yoshida M, Kambayashi M, Hashimoto K (2008) Is the metabolic syndrome an intracellular Cushing state? Effects of multiple humoral factors on the transcriptional activity of the hepatic glucocorticoid-activating enzyme (11 $\beta$-hydroxysteroid dehydrogenase type 1) gene. Mol Cell Endocrinol 285: 10-18.

35. Anagnostis $\mathrm{P}$, Athyros VG, Tziomalos K, Karagiannis A, Mikhailidis DP (2009) The pathogenetic role of cortisol in the metabolic syndrome: a hypothesis. J Clin Endocrinol Metab 94: 2692-2701.

36. Harwood HJ Jr (2005) Treating the metabolic syndrome: acetyl-CoA carboxylase inhibition. Expert Opin Ther Targets 9: 267-281.

37. Corbett JW (2009) Review of recent acetyl-CoA carboxylase inhibitor patents: mid-2007-2008. Expert Opin Ther Pat 19: 943-956. 